\title{
Intervention Strategies for the Improvement of Students' Academic Performance in Data Structure Course
}

\author{
Regina A. Garcia and Lilac A. Al-Safadi
}

\begin{abstract}
The study is intended to recommend intervention strategies which can be used in teaching Data Structure course effectively to undergraduate program in the field of computing and information technology. Descriptive method, formal assessment which is the actual grades of the students, and informal interviews among instructors were utilized in the study. The formal assessment results revealed that $39 \%$ of students in the course have poor academic performance in the course. This concluded that there is a need for intervention strategies which requires planning and implementation to strengthen the motivation of the students to study, boost their academic performance, and uplift the quality of education in the area of computing and information technology
\end{abstract}

Index Terms-Academic performance, data structures, information technology, quality education.

\section{INTRODUCTION}

fThe students' academic performance is the results of the examinations, assignments, quizzes, attendance and other graded points related to the course. It contributes to the standards of the quality of education that every university is aiming for.

The important mission of each higher education institutions in the field of computing and information technology is to provide high quality and relevant education in order to produce skillful and competent conscientious graduates. To achieve this, a number of practical and instructional strategies were designed to improve the students' academic performance.

Data Structure course is one of the requirements to obtain a degree in most computing and information technology academic programs. It has been claimed by many students of different generations that Data Structure course is one of the courses that they have difficulty because it is too abstract and requires higher analytical and problem solving skills. Thus, to improve the performance of struggling students in Data Structure course, intervention strategies are needed.

Intervention strategies are the systematic instructions to promote progress in an area where there is a need for it [1]. In education, they are designed to improve academic performance of students which have specific and measurable objectives. Intervention strategies are based on the academic performance of students and the monitoring of students' progress is necessary. The purpose of intervention strategies in education is to identify all factors that may improve

Manuscript received September 19, 2013; revised December 16, 2013. This work was supported in part by Saudi Electronic University.

Regina A. Garcia was with City College of Calamba, Philippines (e-mail: gigi_0219@yahoo.com).

Lilac A. Al-Safadi is with Saudi Electronic University, Riyadh, Saudi Arabia (e-mail: 1.alsafadi@seu.edu.sa). students' performance academically. Another definition stated that intervention strategies may include school staff, parents, students, and other staff working in relation to students' academics [2]. This could be a part of the university strategies specifically when the teaching professionals and other staff collaborate; this will improve former's skills in classroom management and expand their teaching techniques and strategies. Instructors have usually found ways for classroom strategies that will reach out and help the students to boost their performance. As emphasized, there is a need for intervention strategies in order to meet the needs of students most especially the struggling ones [3].

\section{A. Statement of the Problem}

The average of students' academic performance in Data Structure course for over the years in undergraduate program of computing and information technology in many universities can be concluded as satisfying compared to other courses in the field. However, the percentage of students with poor academic performance every semester is undeniable and do not support the mission of many academic programs. This affects the quality of education the academic programs are trying to maintain. Improving the academic performance of students is part of the continuous improvement to uplift the standard of education in the area of computing and information technology.

\section{B. Objectives of the Study}

The objectives of the study are 1) to identify the characteristics of students in Data Structure course, 2) to identify the academic performance of students in the course, and 3) to recommended intervention strategies to improve the students' performance in Data Structure course.

\section{Significance of the Study}

The study aims to assess the academic performance of students in Data Structure course which resulted in the recommendation of additional intervention strategies needed to improve the students' academic performance. Specifically, the study is beneficial to 1) students, to boost their academic performance in Data Structure course and to help them recognize the value of learning each course of their chosen field, 2) instructors, to assist them in the area that their students needed, helping them to make the course appealing to their students, 3) curriculum development committee, to review the course as a whole, focus on the area that is needed by the students, and recommend necessary actions to assist the department in maintaining the quality of education, 4) computing and information technology academic departments and institutions, to help them maintain the standard of the quality of education that they are providing to the community, and 5) future researchers, to study on how to assist students of Data Structures course in improving their 
academic performance.

\section{Conceptual Framework}

This section proposes the conceptual framework treated in this study. The quality of input influences the quality of output of which in this research are students' academic performance and IT education in the country [4].

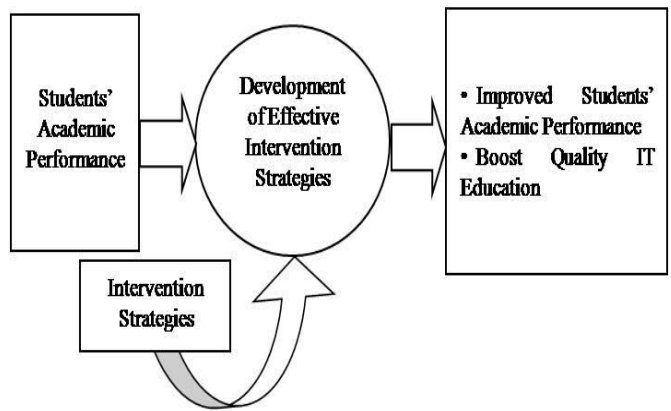

Fig. 1. Research paradigm.

Fig. 1 shows the relationship of students' academic performance with the intervention strategies. The independent variables shown in the figure are the students' academic performance which is their GPAs in the course. The intervening variables are the intervention strategies that are modified and recommended. Those variables are processed in order to have improved students' academic performance and improve the quality of education in the area of computing and information technology.

\section{RESEARCH METHODS}

The study was conducted in an academic institute which offers bachelor degree in computing and information technology. Descriptive method was employed by identifying the characteristics of the students of Data Structure course. Students' grades for each term during the semester were utilized to determine the progress of the students in Data Structure course and identify which part of the term the students have difficulty. Aside from the students' actual grades, informal interviews with some faculty members were conducted in order to gather additional information that is required in this study.

\section{PRESENTAtion OF DATA}

The data presented below are the information related to Data Structure course. Performance Based Assessment of Learning is utilized in the study to further evaluate the need for intervention strategies. The said assessment is the actual student's academic performance in the course. And the improvement of students can be measured through seatwork, quizzes, examinations, and laboratory or hands-on exercises.

\section{A. Course Description}

Data Structure course is one of the courses required in most of the bachelor degrees in computing and information technology. The prerequisite for this course is Programming and Logic Formulations on which students will be provided with the fundamentals that they needed for logic formulations, algorithms and understanding of the object-oriented programming language. Data Structure course will also be a requirement course in order for the students to take Advanced Programming courses where the topics that they are going to discuss have a relationship with the topics in data structures. It means that the higher level courses are application of what the students have grasped in Data Structure course.

The course covers the importance of information hiding and the use of abstraction in program design. Variety of sorting and searching techniques is covered in the course as well as the performance of each which they will use for comparison. In terms of data structures and its implementation, arrays, stacks, queues, linked lists, mappings, trees, sets and graphs will be included as one of the topics. In terms of internal and external searching and sorting; dynamic storage management trees, binary, search, height-balanced trees, and heaps will be included in the discussion. While in terms of graphs, depth-first traversal, breadth-first traversal and shortest/cheapest path algorithms will be discussed in the course.

With Data Structure course, the students are expected to have the ability to identify and design the data structure that will be suited to solve a particular given problem. In Data Structure course, students learn to design alternative implementations of a data structure and construct an efficient algorithm.

The laboratory hours of the course is usually used for the hands-on application of the topics discussed in the lecture.

As of the overall grade upon the completion of the course, $30 \%$ of the grade will be from prelim grading period, $30 \%$ from midterm grading period, and $40 \%$ will be from the final grading period.

\section{B. Students' Profile}

The students in Data Structure course are mostly second year students of most of the bachelor degrees in computing and information technology who have completed basic computer programming and logic formulation courses. Their ages range from 18 to 25 years old.

\section{First Semester 2008/2009}

The succeeding paragraphs discuss the results of the students' academic performance in the course during first semester of the Academic Year. First semester is the regular semester where the course has been regularly offered by the department. It is only offered during second semester depending on the number of students who petition to offer the course. To grant the petition of students, a required number of students are needed to meet in order for the course to be offered during a particular semester.

\section{1) Preliminary grade distribution}

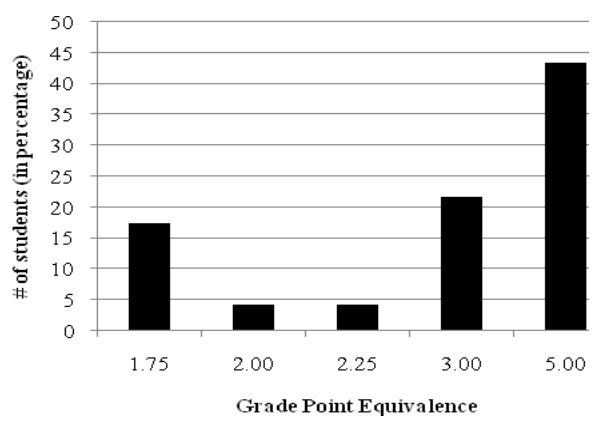

Fig. 2. Preliminary grade point distribution of students in data structure course (1st semester) 
This section discusses the academic performance of the students during the preliminary period of the academic year in which the study was conducted. The grading period covers the introduction to data structures, data types, structured data types, abstract data types, lists, iterators, and performance measurement. Below are figures that show the progress of the students during this period.

Fig. 2 reveals that the average grade of students during preliminary period is 3.49 .

\section{2) Midterm grade distribution}

This section discusses on the academic performance of the students during the midterm period of the academic year in which the study was conducted. This grading period covers sorting, searching, stacks, queues, and dequeues. Below are figures that show the progress of the students during this period.

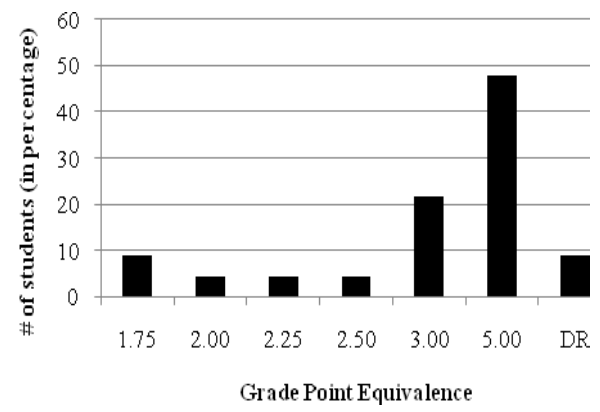

Fig. 3. Midterm grade point distribution of students in data structure course (1st semester).

Fig. 3 reveals that the average grade of students during preliminary period is 3.49 .

\section{3) Finals grade distribution}

Below are the figures in terms of the overall academic performance of the students upon their completion of the course.

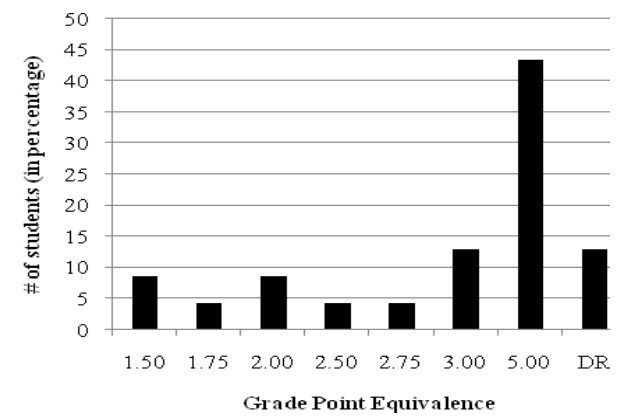

Fig. 4. Finals grade point distribution of students in data structure course (1st semester).

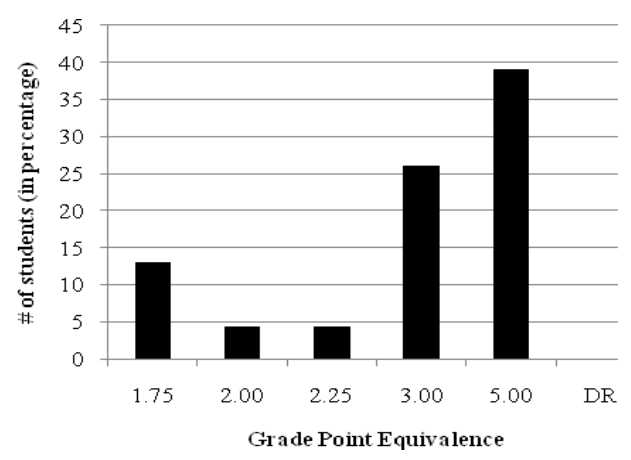

Fig. 5. Overall GPA distribution of students in data structure course (1st semester).
Fig. 4 reveals that the average grade of students during final period is 3.17 which quite improve compared with the two grading period.

\section{4) Overall GPA distribution}

Fig. 5 reveals that the average grade of students is roughly D during this semester of the Academic Year.

\section{ANALYSIS OF RESUltS}

The following paragraphs are the analysis of the data presented in the previous sections.

During the first semester, the GPA average of students in Data Structure course corresponds to D grade which is an equivalent to an average of 3.15 . It was officially reported that $39 \%$ of student obtained poor academic performance upon their completion of the course.

The figures revealed that most of the topics that are covered in the course were difficult based on the level of the students. Among these topics, the most difficult topics for the students based on their performance in the course are the topics covered in the preliminary and midterm period. This was shown by the average GPA during the two periods is 3.49 compared to the average GPA during finals which is 3.17. But the results of the overall average GPA still indicates that the students found the course as difficult to grasp due to the higher analytical skills it requires.

Furthermore, these results of the average GPAs can be explained by the comments of instructors that students have poor attendance, lack of interest in the course and a problem with their study habits. Poor attendance has a negative effect on students' academic performance [5]. Also, problem with study habits might be the results of seeing the course difficult to grasp and this resulted from being not interested in the course. In connection to this, the students seem to have a weak background in basic programming as well as logic formulations which resulted to poor logical thinking and analysis skills as well as programming skills.

The department is using the consultation hours required for each instructor as one of the strategies of the department in order to assist the students who have faced difficulty in the course. But this has seldom used by many students according to the instructors which due to the statements in the previous paragraphs.

The above analysis indicates that intervention strategies are needed in order to improve the students' academic performance in Data Structure course and the quality of education that most universities in the field of computing and information technology would like to achieve and maintain.

\section{RECOMMENDED INTERVENTION STRATEGIES}

Below are the recommended intervention strategies that would help the students to improve their academic performance in the Data Structure course. The selection of these strategies is based on the educational settings and culture of Saudi Arabia.

1) Tutoring. Tutoring is designed to meet the needs of the students and to promote better grades in university, better behavior and be motivated in their studies [6] This should be used to assist the students in coping with 
the course. It is also used to help the students to understand further the topics that have been covered in their classroom. Since the consultation hours of the instructors are not effective for students, tutoring could be best for them to learn better. The results of this proposed tutorial program as intervention strategy is best seen in the students' academic performance. In most scenarios, tutorial is often translated into a "mini-lecture" and having large tutorial class causes students to become passive learners. Thus, tutoring program should not be on the same venue rather it should be in a place where participation is encouraged [7].

2) Student support program. This program includes mentoring, counseling, advising, guidance, and tutoring. This will also allow the fellow students to provide academic support through extra lessons, remedial lessons which should be facilitated or supervised by a qualified and dedicated person who supports the department's vision. It is noted to the department that in order for the tutor to be effective, the tutoring style should match with the students' learning style. As defined, learning style refers to the individualized ways we take in, process, and organize information [8]. And the learning style is categorized as visual, auditory, and kinesthetic learning styles. Visual learning style is the students work best when they are able to see it. Auditory learning style is the students work best when they are able to hear it. While kinesthetic learning style is the students work best when they are doing it or physically involved with it.

3) Behavior support program. Students' behaviors have an impact on their academic performance. Students who demonstrated disruptive behavior is academically weak and they usually perform worse when they had to show their learning results [9]. In this scenario, zero tolerance can be applied but only if the associated policy or code of conduct is approved by the university. This is actually a suggestion to the university itself that code of conduct should be reviewed regularly; ethic of care and accountability is connected with the proper counseling strategy which is always present at the university.

4) Life skills program. This includes mega-skills which are needed in order to have a successful life [10]. The said skills involve disciplined work habits, caring attitudes, and the ability of a person to manage his/her own opportunities and these are all necessary for success. Students need these skills for their growth and development and when these skills are possessed, improvement of their academic performance is possible.

5) External support program/Parental involvement program. Universities neglected the involvement of parents in students' academic performance and this is the result why some university failed due to its unwillingness to involve parents in its program development and implementation [11]. This has been suggested that if students are properly guided, then they will be able to know their abilities and competencies and there will be higher possibilities that they will perform well academically [12].

6) Instructor's Capacity Building. This will cover the instructors' opportunity to develop and improve their teaching skills not only concentrate on the knowledge that they have as far as the course is concerned. Instructors who have learned from various professional development seminars, conferences, etc. be given a chance to provide opportunities for instructors to teach other instructors as well.

7) Integrate Warm-Up Activities. Warm-up activities in class can be beneficial for students who have not fully mastered prerequisites. An important warm-up activity would be asking the students to complete several problems in OOP and discussing solutions.

8) Using Small Groups. Having students work in small groups or in student pairs is an effective instructional strategy especially for struggling students. In small groups, struggling students are more likely to ask questions and benefit from explanations from fellow students. Differentiate teaching strategy. Since data structure is abstract, various instructional techniques (mconceptula models, real-life examples, technologies, and symbolic representations) are needed to be used to best address the different learning styles of students and reach all students.

9) Emphasize Real-Life Applications. This helps students see the value and application of the abstract data structure they are studying by presenting as many real-life applications as can. In addition, it can help increase a student's interest in the course as it becomes more meaningful Changing Seating Arrangements. Physical seating is an important intervention strategy. It helps students focus and increase their interest.

\section{CONCLUSION}

The intervention strategies are excellent assistance to boost the academic performance of students in Data Structure course. These are designed to uplift the standard of education in the field of computing and information technology that an undergraduate program has been providing to young citizens for over the years. The presentation and analysis of data that has been revealed in the study and the suggested intervention strategies will help students to improve the students' academic performance in the course as well as strengthen the strategy that any undergraduate program in computing and information technology regardless of which country. Furthermore, further research is highly recommended to test the effectiveness of a particular intervention strategy in improving academic performance of students in the course and boosts the quality of education in the field of computing and information technology.

\section{REFERENCES}

[1] F. D. Mahlo and M. J. Taole. (November 2012). Intervention Strategies to Improve Student Performance. [Online]. Available: http://www.sacpo.co.za/downloads/conference\%20papers/Interventio n\%20Strategies\%20To\%20improve\%20Student\%20Performance.pdf

[2] P. Munn and G. Lloyd. (1998). Discipline In Schools. A Review of extent causes and cures - Section 5: Intervention Strategies. A Literature Review for the Scottish Office. [Online]. Available: http://sitc.co.uk/dealing_with_disruption/SITE/Resources/SMAR13a. pdf

[3] Eye on Education. (2012). [Online]. Available: http://www.eyeoneducation.com/bookstore/client/client_pages/sample chapters/7213-0.pdf 
[4] Y. Acato, Quality assurance vital. New vision, University Guide 2006/2007, 2006

[5] N. Harb and A. El-Shaarawi. (2006). Factors Affecting Students' Performance.

[Online].

Available: http://mpra.ub.uni-muenchen.de/13621/1/MPRA_paper_13621.pdf

[6] S. Gibbs. (December 2012). Effective Tutoring: Assembling the Pieces. [Online]. Available: https://www.mheonline.com/assets/sra_download/EarlyReadingTutor/ MoreInfo/TutoringWhitePaper_FNL.pdf

[7] G. S. Ng and S. Foo. (1996). Journal of Teaching Practice. [Online]. Available: http://www.ntu.edu.sg/home/sfoo/publications/1996/96 jotp_fmt. pdf

[8] J. Truschel. (2012). Habits of a Highly Effective Tutor. [Online]. Available: http://www.myatp.org/wp-content/uploads/2012/06/ Synergy-Vol-1-Truschel.pdf

[9] R. Mestry, K. C. Moloi, and A. N. Mohamed, "Perspectives on Zero Tolerance to Discipline towards Maintaining a Nurturing and Secure School Environment," Africa Education Review, vol. 4, no. 2, pp. 96-97, 2007.
[10] D. R. Megaskills, Building Children's Achievement for the Information Age, Boston: Houghton Mifflin Company, 1997.

[11] D. Hopkins, International Handbook of Educational Change, Netherlands Klamer Academic Publishers, 1998

[12] I. Mushtaq and S. N. Khan, Factors Affecting Students' Performance, Global Journal of Management and Business Research, vol. 12, no. 9, June 2012.

Regina A. Garcia is an MBA graduate from Laguna College of Business and Arts, Philippines and a bachelor of science in computer science graduate from University of Perpetual Help System-Laguna, Philippines.

Lilac A. Al-Safadi is a Ph.D graduate from University of Wollongong, Australia with a degree of Ph.D. in computer science. In the same institution, she studied master in computer science, graduated with High Distinction, specialized in software engineering. She did her bachelor degree at King Saud University, Riyadh, Saudi Arabia. 